\title{
Editorial
}

\section{FFR-Is It Reliable and Sufficient Tool in Stable Patients?}

\author{
Jeethender Kumar Kala ${ }^{1}$ \\ ${ }^{1}$ Department of Cardiology, Nizam's Institute of Medical Sciences \\ (NIMS), Hyderabad, India
}

Ind J Car Dis Wom 2019;4:177-178

Fractional flow reserve (FFR) is a tool for assessment of significance of intermediate coronary lesions. ${ }^{1-3}$ It is useful not only in the single coronary lesion, but also in the multivessel disease (MVD). ${ }^{4}$ When angiographically tighter triple vessel disease (TVD) is seen, then the decision may be taken for coronary bypass surgery depending on the anatomical severity. In fact, if functional assessment is done with FFR, then true TVD or not can be known, which may change the revascularization modality of treatment.

The three important randomized controlled trails on FFR (FAME-2, ${ }^{5}$ DANAMI-3-PRIMULTI, ${ }^{6}$ and COMPARE-ACUTE ${ }^{7}$ ), where deferred revascularization depending on the FFR value, showed that it was safer, even though the last two trials were done in acute coronary syndrome (ACS) patients. On contrary, this present study ${ }^{8}$ shows that the incidence of target lesion failure in intermediate stenosis with deferred revascularization (FFR > 0.8 ) was high (5.8\%).

Shabbir et al, ${ }^{8}$ in their study, suggested that predicting 1 -year rates of deferred lesion intervention (DLI) based on simple characteristics available at the time of index FFR measurement was presence of diabetes mellitus, left ventricular dysfunction, and ACS presentation. But this proposition is also controversial. If patients categorized as high risk for DLI and who have an FFR of 0.8 to 0.85 will have better clinical outcomes with intervention at the time of index cardiac catheterization is still unknown, and the use of this risk model in conjunction with FFR may lead to improved patient outcomes. ${ }^{9}$

There are multiple limitations to the study.

First, it is a descriptive observational study where 102 patients with 104 lesions are treated. Randomized design with large cohorts is required to validate the findings.

Second, the site of the intermediate stenosis is not taken into account. In one study, "Significance of intermediate values of FFR in patients with CAD,"10 the authors concluded that in intermediate stenosis with FFR in and around the gray zone "bears a major prognostic impact, especially in proximal lesions of left anterior descending artery (LAD). In this regard, deferring revascularization in proximal LAD, especially the gray zone FFR, is not appropriate, where clinical decision and additional physiological indices need to be considered.

Third, only chronic stable angina patients are included in contrary to a real-world scenario where ACS patients are major challenging to treat.

Fourth, single vessel disease is taken, and MVD is excluded where the estimation of FFR is challenging.

DEFINE-FLAIR and iFR-SWEDEHEART trials showed the importance of other modalities of physiological assessment of coronary lesion, that is, instantaneous wave-free ratio (iFR). According to these authors, iFR is noninferior to FFR in predicting the clinical outcomes (especially for the ischemia-driven revascularization). ${ }^{11,12}$ Recently, multiple coronary diastolic phase indices are introduced which requires validation.

\section{Conflict of Interest}

None declared.

\section{References}

1 Fearon WF. Percutaneous coronary intervention should be guided by fractional flow reserve measurement. Circulation 2014;129(18):1860-1870

2 Pijls NHJ, van Schaardenburgh P, Manoharan G, et al. Percutaneous coronary intervention of functionally nonsignificant stenosis: 5-year follow-up of the DEFER Study. J Am Coll Cardiol 2007;49(21):2105-2111

3 Bech GJ, De Bruyne B, Pijls NH, et al. Fractional flow reserve to determine the appropriateness of angioplasty in moderate coronary stenosis: a randomized trial. Circulation 2001;103(24):2928-2934

4 Ragosta M, Bishop AH, Lipson LC, et al. Comparison between angiography and fractional flow reserve versus single-photon emission computed tomographic myocardial perfusion imaging for determining lesion significance in patients with multivessel coronary disease. Am J Cardiol 2007;99(7):896-902

5 De Bruyne B, Pijls NHJ, Kalesan B, et al; FAME 2 Trial Investigators. Fractional flow reserve-guided $\mathrm{PCI}$ versus
Address for correspondence

Jeethender Kumar Kala, MD, Department of Cardiology, Nizam's Institute of Medical Sciences (NIMS), Hyderabad, Telangana 500 082, India (e-mail: jeetu_jain24@yahoo.com).
DOI https://doi.org/ 10.1055/s-0039-3402590
C2019 Women in Cardiology and Related Sciences

\section{License terms}

(이요 $\Theta \circledast$ 
medical therapy in stable coronary disease. N Engl J Med 2012;367(11):991-1001

6 Engstrøm T, Kelbæk H, Helqvist S, et al; DANAMI-3-PRIMULTI Investigators. Complete revascularisation versus treatment of the culprit lesion only in patients with ST-segment elevation myocardial infarction and multivessel disease (DANAMI-3PRIMULTI): an open-label, randomised controlled trial. Lancet 2015;386(9994):665-671

7 Smits PC, Abdel-Wahab M, Neumann FJ, et al; Compare-Acute Investigators. Fractional flow reserve-guided multivessel angioplasty in myocardial infarction. $\mathrm{N}$ Engl J Med 2017;376(13):1234-1244

8 Shaik SA, Sunitha A, Garre I, Lakshmi VSB. Outcomes of deferred revascularization following physiological coronary assessment using fractional flow reserve. Ind J Car Dis Wom 2019; 4(4):190-194
9 Depta JP, Patel JS, Novak E, et al. Risk model for estimating the 1-year risk of deferred lesion intervention following deferred revascularization after fractional flow reserve assessment. Eur Heart J 2015;36(8):509-515

10 Adjedj J, De Bruyne B, Floré V, et al. Significance of intermediate values of fractional flow reserve in patients with coronary artery disease. Circulation 2016;133(5):502-508

11 Davies JE, Sen S, Dehbi H-M, et al. Use of the instantaneous wave-free ratio or fractional flow reserve in PCI. N Engl J Med 2017;376(19):1824-1834

12 Götberg M, Christiansen EH, Gudmundsdottir IJ, et al; iFR-SWEDEHEART Investigators. Instantaneous wave-free ratio versus fractional flow reserve to guide PCI. N Engl J Med 2017;376(19):1813-1823 